\title{
Imagem da biblioteca pública na Sociedade da Informação
}

\author{
The image of the Public Library in Information Society
}

\begin{abstract}
Maria Cleide Rodrigues Bernardino
Doutoranda em Ciência da Informação, pela Universidade de Brasília, UnB. Professora Assistente do Curso de Biblioteconomia da Universidade Federal do Ceará, Campus Cariri E-mail: cleide@cariri.ufc.br

Emir Jose Suaiden Professor Titular da Faculdade de Ciência da Informação da Universidade de Brasília, UnB. Diretor do IBICT. E-mail: emir@unb.br
\end{abstract}

\section{Resumo}

A biblioteca pública ocupa lugar de destaque na sociedade da informação por trazer em sua essência o tratamento, uso e disseminação da informação, que associada às tecnologias da informação e da comunicação garante ao usuário a recuperação precisa da informação. Por sua vez, para que essa recuperação se efetive são necessários profissionais habilitados e conhecedores dos recursos e estratégias permeadas pela sociedade da informação; e aparato tecnológico suficiente que suporte estas atividades. Neste sentido, a história traça uma imagem da biblioteca pública que vai do erudito ao desnecessário, dependendo da época e contexto. Porém, é inevitável a reflexão acerca da mudança de paradigmas que circundam o arcabouço em torno da imagem da biblioteca pública, que na sociedade da informação deverá ter sua imagem associada a outros significados estéticos próprios do contexto em que estamos vivendo. Para entender o termo imagem, nos basearemos em Villafañe (1998), que atribui seu conceito à representação da assimilação de um determinado produto, serviço ou situação na mente das pessoas. Essa ideia faz parte da cultura organizacional da biblioteca e é construída a partir da autoimagem da organização, de sua imagem intencional e funcional. Essa concepção com base na teoria da Gestalt (psicologia) e institucional (administração) ajudarão a desenhar o quadro referencial de apoio para a construção da imagem da biblioteca pública.

Palavras-chave: Biblioteca Pública. Imagem da Biblioteca Pública. Biblioteca Pública - Sociedade da Informação.

\begin{abstract}
The Public Library occupies a prominent place in the information society by bringing in its core processing, use and dissemination of information, which related to information technology and communication ensures the user needs to recover information. In turn, that this recovery are needed to become effective professionals qualified and knowledgeable resources and strategies permeated by information society and technological apparatus sufficient to support these activities. In this sense, the story draws a image of the public library that ranges from classical to unnecessary, depending on the time and context. However, it is inevitable reflection about the paradigm shift that surround the scaffold around the image of the public library, which in the information society should have his image in association with other aesthetic meanings themselves the context in which we live. To understand the term image, we will base on Villafañe (1998), which gives his concept of assimilation to the representation of a particular product, service or situation in people's minds. This idea is part of organizational culture and the library is constructed from the self-image of the organization, its image intentional and functional. This concept based on Gestalt theory (psychology) and institutional (management) will help draw the frame of reference to support for building the image of the public library.
\end{abstract}

Keywords: Public Library. Image of the Public Library. Public Library - Information Society.

InCID: R. Ci. Inf. e Doc., Ribeirão Preto, v. 2, n. 1, p. 130-142, jan./jun. 2011. 


\section{Introdução}

O termo imagem será tratado aqui no sentido de identidade, perfil da instituição. Ao associarmos o termo a outros, no sentido de campo de atuação, como: organização, instituição, corporação, estes nos conduzem a expressões como, por exemplo: perfil institucional, identidade corporativa, imagem organizacional, imagem corporativa, identidade institucional, imagem institucional.

A imagem será uma representação da assimilação das pessoas sobre os produtos da comunicação visual, processos da conduta humana, como pensamento, percepção e até mesmo memória. (VILLAFAÑE, 1998, p. 23). O que significa que, no que diz respeito a uma organização, sua imagem será em primeiro lugar, como ela se enxerga e se compreende em segundo, como se projeta para a comunidade e em terceiro, como se estrutura e se relaciona com seu público.

Segundo o dicionário, imagem é a representação de pessoa, coisa ou uma idéia. Para uma instituição, a imagem pode ser entendida como "um registro público dos atributos identificadores da organização". Ou seja, uma "representação coletiva de um discurso imaginário, correspondente à leitura e à interpretação que a sociedade, ou cada um dos seus grupos ou estratos, têm e constroem de modo intencional ou espontâneo a respeito de determinada organização". (CHAVES, 1996, p. 11).

Ao entender imagem como uma ideia, "reprodução, no espírito, de uma sensação na ausência da causa que a produziu", , foi nos dado, de forma clara e incontestável, a liberdade para ampliar o campo de aplicação da palavra. Dessa forma, podemos dizer que imagem é a "representação simplificada que emerge na mente, como síntese de uma ou várias sensações ou percepções”. (POYARES, 1998, p. 87). Poyares (1998, p. 88) diz ainda que da coincidência de formas dessas percepções na mente em diversos indivíduos, nasce o que chamamos de imagem pública.

\section{Teoria da Gestalt e Teoria Institucional}

Para dar apoio a concepção de imagem da biblioteca pública, usaremos a teoria gestáltica, cujo principal foco é a percepção de que os elementos e os detalhes de um conjunto

\footnotetext{
${ }^{1}$ Ver Pequeno Dicionário Brasileiro da Língua Portuguesa.

InCID: R. Ci. Inf. e Doc., Ribeirão Preto, v. 2, n. 1, p. 130-142, jan./jun. 2011.
} 
é significativamente afetada pela percepção do conjunto como um todo. Sua premissa é a máxima o todo é maior do que a soma das suas partes. De acordo com a teoria gestáltica, não se pode ter conhecimento do "todo" por meio de suas partes, pois o todo é maior que a soma de suas partes (RODRIGUES, 2000, p. 19).

Estuda a percepção e a sensação do movimento, os processos psicológicos envolvidos diante de um estímulo e como este é percebido pelo sujeito. Do ponto de vista do processo, a imagem é um conceito construído na mente do público, a partir de um estímulo não necessariamente real, que é corrigido por esse público através de um trabalho perceptivo e cujo resultado pode ser explicado em termos de isomorfismo gestáltico entre o estímulo e a experiência anterior.

Neste sentido, a teoria gestáltica é adequada por situar a imagem como o resultado de um processo de assimilação por parte do receptor, que metaboliza um conjunto de estímulos transmitidos. Esse processo de formação da imagem da organização, no caso aqui, a biblioteca pública, reúne como elementos principais: a identidade da organização - os estímulos; a imagem - que corresponde ao conceito que o público tem da organização; e um trabalho corporativo - que é responsável pela diferença entre as percepções. Um interferindo no outro e se retroalimentando, em um processo contínuo. Dessa forma, a imagem de uma organização corresponde ao conjunto de características e atributos que definem sua essência.

Para entender a cultura organizacional da biblioteca pública, de como é criada, mantida e percebida, usaremos a teoria institucional, que "permite uma visão múltipla das pressões externas e internas na construção de uma nova arquitetura organizacional”. (QUINELLO, 2007, p. 156).

A perspectiva institucional em estudos organizacionais, tem se dedicado a diferentes temáticas, dentre elas está a consideração de que estruturas e rotinas organizacionais são reflexos ou decorrências de normas institucionalizadas contextualmente, o que remete a questões ligadas à legitimidade e à própria concepção de ambiente da organização.

Para Rosetto e Rosetto (2005, p. 5), a perspectiva institucional para o estudo das organizações pode ser, "uma abordagem simbólico- interpretativa da realidade organizacional, apresentando uma posição epistemológica predominantemente subjetivista, na qual é salientada a construção social da realidade organizacional". 
Destacamos aqui a importância das relações entre a organização e o ambiente, considerando a cultura e sua influência sobre elas. Para uma interpretação mais adequada das ações organizacionais, é relevante considerar o mercado junto às condições culturais e sociais. A perspectiva institucional enfatiza os elementos culturais e sociais da sociedade e das organizações.

Dentro da visão institucional as organizações são compostas por duas dimensões essenciais: a técnica e a institucional. O ambiente técnico caracteriza-se pela troca de bens e serviços, enquanto o ambiente institucional conduz o estabelecimento e a difusão de normas de atuação, necessárias ao alcance da legitimidade organizacional.

\title{
Imagem da Biblioteca Pública e Cultura Organizacional
}

Enquanto instituição pública, a biblioteca pública, constrói sua imagem organizacional, pelo somatório do cumprimento de funções, oferecimento de produtos e serviços de qualidade e necessários para a comunidade, mas, sobretudo, pela projeção desses serviços para a comunidade e por sua vez, esta projeção é resultado de como a instituição se percebe e se estrutura tecnologicamente e comercialmente.

Assim, como afirma Araújo (1999, p. 44),

\begin{abstract}
A imagem de uma determinada organização pode ser entendida como o resultado da integração de um conjunto de imagens na mente dos públicos com os quais a organização se relaciona, que, com maior ou menor importância, são projetados para o exterior.
\end{abstract}

A imagem da organização como ativo intangível, será o entendimento da imagem ultrapassando as fronteiras da identidade visual, da publicidade e da propaganda, porém, compreendendo a totalidade da organização, seus produtos e serviços (como se projeta para a população), a cultura da instituição e as pessoas envolvidas, (como ela se vê e se percebe), os processos de comunicação interna e externa e as relações com a comunidade (como se estrutura tecnológica e comercialmente).

Na organização, esses pontos são o que chamaremos aqui de variáveis independentes: autoimagem; imagem intencional; e imagem funcional da organização. 


\section{Autoimagem}

Chaves (1996, p. 22) descreve autoimagem como a "imagem interna, construída a partir da percepção que a organização tem de si mesma”, é a parte da identidade da organização, sua orientação estratégica, sua política de recursos humanos, sua cultura corporativa e seu clima interno. Ou seja, é um conjunto de atributos assumidos como próprios pela organização, sua cultura organizacional e sua missão.

A autoimagem para a biblioteca pública será compreendida pelo conjunto de valores compartilhados pelos membros que a compõem. Esses valores são histórica e socialmente construídos, entretanto, essa percepção se constrói e desconstrói à medida que recebe um somatório de insumos, que podem ser ações, atitudes, fatos, sistemas, isolados ou não.

O sucesso da biblioteca pública como organização, depende da autoimagem desta, da compreensão por parte dos membros que compõem a biblioteca pública de sua cultura organizacional, qual sua razão de existência - que corresponde à missão -; quais seus valores, que serão responsáveis pelo sucesso da organização; as estratégias e os objetivos da instituição.

Para Schein (1985 apud FREITAS, 2008, p. 33) cultura "é um aprendizado coletivo que um grupo desenvolve para cuidar de sua adaptação externa e questões internas”. Essa concepção, por parte dos membros que compõem a biblioteca pública, é essencial para o desenvolvimento da imagem da biblioteca como um todo, uma vez que é atributo primordial para a composição da identidade da organização.

Fleury e Fleury (1995, p. 24) dizem que:

Cultura organizacional é um conjunto de valores, expressos em elementos simbólicos e em práticas organizacionais, que em sua capacidade de ordenar, atribuir significados, construir a identidade organizacional, tanto agem como elementos de comunicação e consenso, como expressam e instrumentalizam relações de dominação.

Assim, os valores incorporados por uma instituição, como é o caso da biblioteca pública, são incorporados e expressos pelos seus membros e projetados para a comunidade, que por sua vez, constroem significados e conceitos a respeito da organização. O que torna essa variável importantíssima no processo de construção da imagem da biblioteca pública. 


\section{Imagem Intencional}

É a identidade comunicável, como a instituição se projeta para a sua comunidade usuária. É a manifestação da personalidade corporativa da organização, e essa personalidade se desenvolve através das funções de identificação, diferenciação, memorização e associação, envolvendo produtos e serviços, comportamento humano e demais atitudes da organização, ou seja, seu posicionamento estratégico.

A imagem intencional é como a instituição pretende se mostrar. Deve-se verificar a imagem corporativa, financeira, comercial, interna e pública, que pode ser entendido como estrutura corporativa e financeira da instituição, a relevância de seus produtos e serviços, dos recursos humanos, importância cultural e por fim, estudo do ambiente e projeção midiática.

Compreende a identidade visual: logotipo, logomarca, homepage, blog, utilização de elementos visuais em correspondências, publicações, cartões de visitas, cartazes etc; a comunicação interna: sistema organizacional, seus fluxos e níveis formal e informal, setor responsável pelo planejamento e objetivos para viabilizar a interação entre a organização e seus funcionários a comunicação de marketing: composto que compreende a integração e a coordenação dos esforços relativos à publicidade e propaganda, relações públicas etc; e a comunicação institucional: ações personalizadas que possibilitam ao público conceder credibilidade e aceitação dos produtos e serviços.

\section{Imagem Funcional}

A imagem funcional para Chaves (1996, p. 21) corresponde à percepção dos públicos do conjunto de características e condições objetivas e visíveis da organização. Isto inclui a capacidade de operação, a infra-estrutura, o nível de capacitação e a postura das pessoas, o nível de serviço oferecido, os preços praticados, o grau de integração social presente e os relacionamentos da organização com os públicos.

$\mathrm{Na}$ organização trata-se da competência tecnológica e comercial e o relacionamento direto e indireto com a comunidade usuária. É como a organização se estrutura, seu aparato tecnológico, seu espaço físico, equipamentos etc, como os produtos e serviços são oferecidos e como se dá o relacionamento com a população usuária. 
O entendimento e incorporação dessas três variáveis, constrói a cultura organizacional, que por sua vez, é constituída por atores organizacionais, ou seja, pessoas, funcionários, e é por eles reinventada, reconstruída diariamente, resultando na representação imagem da coletividade sobre a instituição. Entretanto, não como uma aglomeração de individualidades, pensamentos pessoais etc, mas como um todo não a soma das partes.

A perspectiva institucional em estudos organizacionais, tem se dedicado a diferentes temáticas, dentre elas está a consideração de que estruturas e rotinas organizacionais são reflexos ou decorrências de normas institucionalizadas contextualmente, o que remete a questões ligadas à legitimidade e à própria concepção de ambiente da organização.

Para Rosetto e Rosetto (2005, p. 5), a perspectiva institucional para o estudo das organizações pode ser "uma abordagem simbólico- interpretativa da realidade organizacional, apresentando uma posição epistemológica predominantemente subjetivista, na qual é salientada a construção social da realidade organizacional”.

Destacamos aqui a importância das relações entre a organização e o ambiente, considerando a cultura e sua influência sobre elas. Para uma interpretação mais adequada das ações organizacionais, é relevante considerar o mercado junto às condições culturais e sociais. A perspectiva institucional enfatiza os elementos culturais e sociais da sociedade e das organizações.

Dentro da visão institucional as organizações são compostas por duas dimensões essenciais: a técnica e a institucional. O ambiente técnico caracteriza-se pela troca de bens e serviços, enquanto o ambiente institucional conduz o estabelecimento e a difusão de normas de atuação, necessárias ao alcance da legitimidade organizacional.

A preocupação com o usuário e o atendimento de suas necessidades informacionais em qualquer suporte é uma premissa da nova era, porém veio junto com a descoberta de que a biblioteca pública não faz parte da paisagem urbana da cidade, assim como os correios, o banco, a praça etc. (BIBLIOTECA PÚBLICA, 2010, p. 31).

Enquanto institucionalmente a biblioteca pública se diz "espaço privilegiado do desenvolvimento das práticas leitoras", com igualdade de acesso a todos, disponibilizando todo tipo de conhecimento, um verdadeiro "elo entre a necessidade de informação de um membro da comunidade e o recurso informacional que nela se encontra organizado e à disposição. (BIBLIOTECA PÚBLICA, 2010, p. 18). Entretanto, “a exigüidade de recursos 
locais impedem as bibliotecas de oferecerem serviços com as qualidades possíveis e desejáveis”. (BIBLIOTECA PÚBLICA, 2010, p. 29).

A falta de bibliotecários nas bibliotecas públicas municipais é uma realidade, como também a "inadequação de suas ações e falta de compartilhamento" (CAVALCANTE, 2010, p. 8) com outros órgãos públicos, como por exemplo, a escola, reflete também na falta de usuários, de atividades cotidianas de incentivo a leitura, acervo desatualizado e um desconhecimento por parte dos usuários do papel da biblioteca pública para com a sociedade. As bibliotecas públicas brasileiras ainda não detêm equipamentos necessários de acesso à informação, acesso a internet, que juntamente com a inadequação do espaço, que se apresenta de maneira desarticulada com os demais órgãos culturais e educacionais.

Neste sentido, tudo é contraditório às diretrizes da sociedade da informação, que no mínimo coloca a biblioteca pública como centro de atividades interativas, de construção e disseminação de informações ininterruptas, sendo um verdadeiro de ligação entre o cidadão e a informação.

\section{O Papel da Biblioteca Pública na Sociedade da Informação}

O discurso da biblioteca pública a coloca em uma posição de busca e conquista do seu espaço quanto à democratização do direito à informação e a necessidade de "assumir um caráter efetivo na vida das pessoas", (CAVALCANTE, 2010, p. 6) tornar-se útil, estabelecer uma vinculação e interação com a comunidade usuária.

Dessa forma, a biblioteca poderá se tornar um "espaço de encontro, de busca, diálogo, prazer, descoberta, aventura, cidadania e fortalecimento dos laços locais" (CAVALCANTE, 2010, p. 10), sobretudo, um espaço agradável e atrativo, que fortaleça não somente o caráter educativo da biblioteca pública, mas sua função social e cultural, permitindo a construção da cidadania. Para que isto aconteça é necessário o estabelecimento de políticas públicas fortes, estruturadas e sérias, investimento consistente no sentido de transformar as bibliotecas em local de inclusão, participação cidadã e sustentabilidade social e informacional, (CAVALCANTE, 2010, p. 11).

Um verdadeiro "espaço multicultural, de troca de saberes e experiências, de aprendizado humano e de atendimento às necessidades informacionais locais" 
(CAVALCANTE, 2010, p. 5), precisa de profissionais bibliotecários qualificados e preparados para atender as demandas da chamada sociedade da informação.

Santos e Carvalho (2009, p. 51) dizem que "na 'sociedade da informação' o uso da informação é a peça chave para que um cidadão possa se tornar um agente ativo [...]". Para que se faça uso da informação, esta deverá estar devidamente processada a fim de que possa ser recuperada, para que haja a disseminação.

A biblioteca pública brasileira apesar de ser considerada um espaço de cultura e conhecimento por excelência, não abrigam em sua estrutura condições necessárias para atuar de maneira eficaz na sociedade da informação. Suaiden (2000, p. 57) diz que "a sociedade da informação traz no seu bojo as questões da globalização, das novas tecnologias e do modelo de desenvolvimento sustentável". Essas questões por sua vez, contradizem a realidade da biblioteca pública brasileira que, enquanto segmento participante da sociedade da informação, ainda vive à margem, com mais atribuições do que realmente pode abarcar e às voltas com a eterna "[...] batalha que trava para responder às inquietações da sociedade sobre seu papel, a biblioteca pública perde cada vez mais prestígio e poder, deixando de ser o grande centro disseminador da informação [...]" (SUAIDEN, 2000, p. 58).

Podemos afirmar que "a biblioteca pública tem a informação como seu permanente objeto de trabalho e a comunicação como processo contínuo do fazer bibliotecário", (CUNHA 2003, p. 69) o que a coloca como parte atuante na sociedade da informação, entretanto, significa também que apesar de ser um segmento institucional necessário à sociedade da informação, não está devidamente equipada a fim de se inserir adequadamente e eficazmente nesta sociedade.

Mattelart (2006, p. 171) diz que, "vocabulário da sociedade da informação se impôs como um logotipo da assim chamada globalização. As duas noções contêm a mesma ambigüidade". A realidade da biblioteca pública deixa esta afirmação bem clara, pois não é apenas por tratar ou ter a informação como objeto de trabalho que a biblioteca pública pode atuar significativamente na sociedade da informação, mas por compreender que faz parte do rol de instituições que dão suporte à chamada sociedade da informação.

Conforme Cunha (2003, p. 72): 


\begin{abstract}
A sociedade da informação, nos diferentes espaços geográficos em que vem sendo concebida, atribui à biblioteca pública a missão especial de assegurar a democratização do acesso em rede, a oferta de produtos e serviços de qualidade que contribuam para diminuir as desigualdades sociais e estimular os usuários a utilizar a internet como instrumento de ampliação de conhecimento e convivência [...]
\end{abstract}

Portanto, o papel da biblioteca pública na sociedade da informação será efetivado quando esta estabelecer relações estreitas com a sua comunidade usuária, tendo-a como foco principal de atuação, sendo imprescindível no que se fizer necessário, proporcionando o acesso à informação em qualquer suporte a qualquer pessoa e em qualquer tempo, inserindo sua clientela no processo global permeados pelo acesso às tecnologias da informação e da comunicação.

\title{
Considerações Finais
}

Flusser (1983, p. 133) diz que para que a biblioteca seja verdadeiramente pública, precisa de uma estruturação de sua gestão e serviços, para que possa participar efetivamente do processo informacional e possa dar a palavra e oferecer seus serviços culturais a todas as categorias sociais, inclusive ao que chama de não-público, os excluídos socialmente.

Há uma necessidade de trazer a biblioteca para mais perto da população, mais participativa e "ciente de sua importância para a construção de uma cidadania plena". (FEITOSA, 1998, p. 21). Repensar seu papel ao longo dos anos foi o que impulsionou a biblioteca pública para rever seus conceitos e aperfeiçoar seus serviços. Milanesi (1986, p. 95) diz que "a dificuldade maior está exatamente em conceituar biblioteca pública", pela amplitude de seu atendimento, pelas diretrizes educativas do Manifesto da UNESCO, pela sua própria deficiência, sobretudo pelas mudanças impostas pelos novos tempos, pela era da informação e do conhecimento.

Conhecer os usuários é necessário para que a biblioteca pública sobreviva frente às exigências da sociedade da informação, Feitosa (1998, p. 34) disse que "a biblioteca pública perecerá se não se retroalimentar com seu público", isto significa que é preciso estratégias consistentes no sentido de trazer a população usuária para dentro da biblioteca.

As bibliotecas públicas brasileiras revelam imagens que se apresentam, ora positiva, ora negativa dependendo do contexto. Uma não elimina a outra, pois ao mesmo tempo em que 
reconhecemos as limitações e problemática da biblioteca pública, também reconhecemos seu potencial, seu valor democrático, social e cultural.

Como orienta o Manifesto da UNESCO, seus "serviços se baseiam na igualdade de acesso a todos" e uma amplitude dessa é passível de falhas. Como afirma Rasche e Varvakis (2006, p. 137), o grande desafio para os gestores da biblioteca pública reside na capacidade de implantar serviços, tendo em vista os ideais norteadores pontuados pelo Manifesto da UNESCO e recriar ou adaptar seu papel à realidade local.

O ideal seria aproveitar as falhas existente, aprofundar ideias e desenvolver estratégias com o objetivo de sanar as deficiências apresentadas e construir uma imagem que ultrapasse os limites do negativo ou do positivo, mas que seja absolutamente necessária para a comunidade como um todo.

Antes de acusar ou enaltecer a biblioteca pública, precisamos fazer valer as diretrizes do Manifesto da UNESCO no intuito de construir uma biblioteca pública cada vez mais democrática, acessível e necessária, vinculada e integrada com a comunidade usuária e condizente com as necessidades da sociedade da informação.

E como parte integrante do cenário da sociedade da informação a biblioteca pública precisa se apropriar das tecnologias da informação e da comunicação, a fim de permitir uma disseminação eficaz da informação e atuar de maneira eficiente e consciente de seu papel na sociedade da informação.

\section{Referências}

ARAÚJO, Jorge de Souza. Imagem organizacional: o caso do posto ecológico da UnB. 1999. 173 f. Dissertação (Mestrado em Administração) - Universidade de Brasília, Brasília, Distrito Federal, 1999.

BIBLIOTECA PÚBLICA: princípios e diretrizes. 2. ed. Rio de Janeiro: Fundação Biblioteca Nacional, 2010.

CAVALCANTE, Lidia Eugênia. Cultura informacional e gestão de bibliotecas públicas municipais: competências e usos da informação. ENANCIB - Encontro Nacional de Pesquisa em Ciência da Informação, 11. Rio de Janeiro, 25 a 28 de outubro. Anais... Rio de Janeiro, ANCIB, 2010. Disponível em:

<http://congresso.ibict.br/index.php/enancib/xienancib/paper/view/128/252> Acesso em: 24 jan. 2011.

InCID: R. Ci. Inf. e Doc., Ribeirão Preto, v. 2, n. 1, p. 130-142, jan./jun. 2011. 
CUNHA, Vanda Angélica da. A biblioteca pública no cenário da sociedade da informação. Biblos, año 4, n. 15, abr./jun., 2003. Disponível em: <http://dialnet.unirioja.es/servlet/articulo?codigo=743225> Acesso em: 26 jan. 2011.

CHAVES, Norberto. La imagen corporativa: teoria e metodologia de la identificación institucional. 4. ed. Barcelona: Gustavo Gili, 1996.

FEITOSA, Luiz Tadeu. O poço da draga: a favela e a biblioteca. São Paulo: Annablume; Fortaleza: Secretaria da Cultura e Desportos, 1998.

FLEURY, Afonso Carlos Corrêa; FLEURY, Maria Tereza Leme. Aprendizagem e inovação organizacional. São Paulo: Atlas, 1995.

FLUSSER, Victor. A biblioteca como instrumento de ação cultural. Rev. Escola de Biblioteconomia da UFMG, Belo Horizonte, v. 12, n. 2, p. 145-169, set., 1983. Disponível em: <http://portaldeperiodicos.eci.ufmg.br/reb/> Acesso em: 21 jan. 2011.

FREITAS, Maria Ester de. Cultura organizacional: evolução e crítica. São Paulo: Cengage Learning, 2008.

MANIFESTO DA IFLA/UNESCO SOBRE BIBLIOTECAS PÚBLICAS. 1994. Disponível em: <http://archive.ifla.org/VII/s8/unesco/port.htm>. Acesso em: 07 fev. 2011.

MATTELART, Armand. História da sociedade da informação. 2. ed. São Paulo: Loyola, 2006.

MILANESI, Luiz. Ordenar para desordenar: centro de cultura e bibliotecas públicas. São Paulo: Brasiliense, 1986.

POYARES, Walter. Imagem pública: glória para uns, ruína para outros. São Paulo: Globo, 1998.

QUINELLO, Robson. A teoria institucional aplicada à administração: entenda como o mundo invisível impacta na gestão dos negócios. São Paulo: Novatec, 2007.

RASCHE, Francisca; VARVAKIS, Gregório. Bibliotecas públicas e seus serviços. In: CUNHA, Miriam; SOUZA, Francisco das Chagas de (Org.). Comunicação, gestão e profissão: abordagens para o estudo da ciência da informação. Belo Horizonte: Autêntica, 2006. p: 127-140.

RODRIGUES, Hugo Elídio. Introdução à gestalt-terapia: conversando sobre os fundamentos da abordagem gestáltica. Petrópolis: Vozes, 2000.

ROSETTO, Carlos Ricardo; ROSETTO, Adriana Marques. Teoria institucional e dependência de recursos na adaptação organizacional: uma visão complementar. ERA Eletrônica, v. 4, n. 1, Art. 7, jan./jun., 2005. Disponível em: <http://www.scielo.br/pdf/raeel/v4n1/v4n1a10.pdf> Acesso em: 07 fev. 2011.

SANTOS, Plácida Leopoldina Ventura Amorim da Costa; CARVALHO, Ângela Maria Grossi de. Sociedade da informação: avanços e retrocessos no acesso e no uso da informação. Informação \& Sociedade: estudos. João Pessoa, v. 19, n. 1, p. 45-55, jan./abr., 2009. 
SUAIDEN, Emir José. Biblioteca pública no contexto da sociedade da informação. Ciência da Informação, Brasília, v. 29, n. 2, 2000. Disponível em:

<http://www.scielo.br/pdf/ci/v29n2/a07v29n2.pdf> Acesso em: 24 jan. 2011.

VILLAFAÑE, Justo. Imagem positiva: gestion estrategica de la imagen de las empresas. Madrid: Pirâmide, 1998.

Artigo submetido em: 31 mar. 2011

Artigo aceito em: 15 abr. 2011 